\title{
A HIPERVULNERABILIDADE DO CONSUMIDOR NO E-COMMERCE CROSS BORDER: O DESAFIO DO MERCADO TRANSNACIONAL
}

\author{
Cássio Bruno Castro Souza* \\ Marta Luiza Leszczynski Salib ${ }^{*}$
}

\section{RESUMO}

A pesquisa pretende analisar as normas que regulamentam a proteção do consumidor brasileiro no comércio eletrônico de caráter transnacional, chamado de e-commerce cross border, tendo em vista a hipossuficiência do consumidor ao firmar contratos virtuais em um cenário de regulamentos múltiplos. O consumidor virtual firma con*tratos no mercado transnacional sem saber efetivamente seus direitos e obrigações assumidas. O método de pesquisa utilizado foi o indutivo com pesquisa bibliográfica, concluindo que há uma lacuna normativa importante na proteção do consumidor no e-commerce cross border, uma vez que demandar neste ambiente é dificultoso pelos custos, língua e diferentes ordenamentos jurídicos.

Palavras-chave: Consumidor; Proteção; E-commerce Cross border; Mercado transnacional; Hipervulnerabilidade.

\section{CONSUMER HYPERVULNERABILITY IN E-COMMERCE CROSS BORDER: THE CHALLENGE OF THE TRANSNATIONAL MARKET}

\begin{abstract}
The research intends to analyze the norms that regulate the protection of the Brazilian consumer in the transnational electronic commerce, called cross border e-commerce, in view of the consumer's hyposufficiency when signing virtual contracts in a multiple regulation scenario. The virtual consumer signs contracts in the transnational market without actually knowing his rights and obligations assumed. The research method used was the inductive with bibliographic research, concluding that there is an important normative gap in consumer protection in cross border e-commerce, since demand in this environment is hampered by costs, language and different legal systems.
\end{abstract}

Keywords: Consumer; Protection; E-commerce cross border; Transnational market; Hypervulnerability.

\section{INTRODUÇÃO}

\footnotetext{
* Doutorando em Ciências Jurídicas pela Universidade do Vale do Itajaí-SC. Mestre em Direito Econômico pela Pontifícia Universidade Católica do Paraná. Professor de Direito da Faculdade Católica de Rondônia. E-mail: cassiocastrosouza@gmail.com.

* Doutoranda em Ciências Jurídicas pela Universidade do Vale do Itajaí-SC. Mestre em Direito, relações Internacionais e Desenvolvimento pela Pontifícia Universidade Católica de Goiás. Professora de Direito da Faculdade Católica de Rondônia.E-mail: marta.salib@fcr.edu.br.
} 
O ato de "comprar" tornou-se um meio de socialização, integração, onde as pessoas se sentem parte de um grupo quando são capazes de trocar informações sobre novos modelos de bolsas, vídeo games, celulares, televisores. A agressividade das empresas de atuação transnacional no uso das ferramentas de Marketing transforma um simples objeto em um sonho de consumo, criando necessidades no consumidor que muitas vezes nem existem. Assim, o "não ter" se torna um fator de exclusão social, incentivando inclusive a homogeneização de padrões culturais, pois todos querem o mesmo produto, da mesma marca e do mesmo modelo.

Essa massificação do consumo e a transnacionalidade da produção ganhou novos contornos com a Internet. A partir dela, o acesso à produtos internacionais e serviços virtuais foi facilitado, pois aproximou consumidores, empresas, governos e entidades das mais variadas ordens. É o chamado E-commerce cross border. Antes, esta interação era feita através do deslocamento das pessoas ao território estrangeiro. O consumidor era o turista que viajava e fazia suas compras em lojas físicas. Com a Rede Mundial de Computadores, surgiu o consumidor cibernético, que tem acesso aos mesmos produtos, mas sem sair de casa.

Esse hábito passou a ser comum entre os brasileiros nas compras de bens de consumo pela Internet, não somente em sítios nacionais, mas também em sítios internacionais, adquirindo no comércio eletrônico internacional desde roupas a carros importados. Porém, não raras vezes, ouvem-se relatos de consumidores que foram surpreendidos com o recebimento de produtos danificados, destoantes do que foi acordado com o fornecedor, ou mesmo, nem os recebem.

Esse consumidor passivo, como veremos no decorrer deste trabalho, firma relações jurídicas consumeristas pela Internet com fornecedores internacionais que, por vezes, só possuem o sítio virtual, sem sede física. Essa situação deixa o consumidor eletrônico altamente vulnerável e exposto às práticas de mercado, o que provoca a necessidade de se discutir e tentar encontrar soluções possíveis no âmbito do Direito Internacional Privado para resolver os eventuais conflitos que possam nascer destes contratos eletrônicos internacionais de consumo.

Como, então, regular esse mercado eletrônico a ponto de proteger o consumidor, parte hipossuficiente da relação jurídica? Na verdade, nem no mercado interno brasileiro a regulação do comércio eletrônico existe de forma amplamente eficaz. No entanto, é possível a 
aplicação do Código de Defesa do Consumidor para dirimir essas contradições e obscuridades na legislação internacional. O objetivo deste trabalho é analisar a fragilidade das normas que regulamentam a proteção do consumidor brasileiro no comércio eletrônico de caráter transnacional, chamado de e-commerce cross border, tendo em vista a hipossuficiência do consumidor ao firmar contratos virtuais em um cenário de regulamentos múltiplos.

Assim, para se alcançar a proposta feita nesse estudo, o artigo foi desmembrado em três pontos. O primeiro será destinado à contextualização sobre a realidade do mundo interdependente, com a qualificação do Estado transnacional e, via de consequência, do mercado transnacional. O segundo será dedicado a introduzir o leitor no mundo do comércio eletrônico, conceituando-o. Em especial, serão tratadas as diferenças existentes entre "contratos eletrônicos internacionais de consumo" dos "contratos eletrônicos internacionais de comércio", pois estes últimos sempre foram o foco de estudo do Direito Internacional Privado e dos diplomas de legislação internacional, enquanto aqueles restaram praticamente esquecidos.

Por fim, o último ponto apresentará uma perspectiva para a construção e consolidação da proteção do consumidor brasileiro no comércio eletrônico internacional, com uma coletânea das principais normas existentes em âmbito mundial que abordam o tema, seja de forma universal ou regional, que possam servir de parâmetro para se chegar a um consenso de como aplicar estas normas para os consumidores cibernéticos brasileiros. A partir destes diplomas jurídicos, será feita uma análise do ordenamento jurídico brasileiro na tentativa de encontrar formas de compatibilizá-lo com o Direito Internacional Privado, com vistas sempre a garantir a proteção do consumidor e minimizar seus riscos neste mercado.

Por se tratar de um tema novo e um modelo de comércio inédito, perceberemos que as normas existentes são insuficientes, o que nos levará a expor os desafios que juristas e Estados enfrentarão para harmonizar o Direito Internacional Privado com as inúmeras legislações nacionais que abordam o tema. A partir disso, será apresentada a ideia de cooperação internacional a fim de se alcançar Princípios únicos em âmbito internacional, uma vez que o dinamismo do comércio eletrônico impede o engessamento do Direito.

Para se chegar ao eficaz desenvolvimento deste trabalho, foi utilizado o método de pesquisa indutivo e o tipo de pesquisa desenvolvido foi o da pesquisa bibliográfica, abrangendo todo estudo já publicamente divulgado em relação ao tema, envolvendo teorias que já receberam um tratamento científico, além da jurisprudência. 


\section{1 - O MODELO DE ESTADO TRANSNACIONAL E O CONSUMO}

A globalização identificada como um processo econômico-comercial através do qual intensifica-se o comércio, a economia e o desenvolvimento tecnológico, impõe a criação de um novo mercado influenciado pelo capitalismo e, consequentemente, um modelo de Estado com inspirações em novas tecnologias, novas estruturas sociais, nova economia e novas culturas (CAPRA, 2002, p.141). Os novos poderes transnacionais, resultados da intensificação do fenômeno da globalização, tornam necessária a democratização das relações entre estados, fundada na cooperação e na solidariedade, assegurando a construção de bases e estratégias de governança, regulação e intervenção transnacionais. (OLIVIERO; CRUZ, 2014, p.23).

Com os novos desafios da globalização, emerge um novo cenário para o Estado, que passa a compartilhar esferas de seu poder e é incitado a debater sobre regulamentação com os novos atores da sociedade internacional. O Estado passou a administrar parcerias com as outras fontes de poder, como empresas, organizações sociais e instituições das mais variadas ordens e a tão almejada eficaz cooperação internacional é desafiada a se consolidar. O novo conceito de soberania é visto não mais como significado de absoluta independência do Estado para se autodeterminar, indicando que, com a revolução tecnológica de meios de comunicação, os bens jurídicos compartilhados pelos países passam a exigir atuação em conjunto.

Assim, neste viés de uma argumentação transnacional, a Globalização seria entendida como uma politização e por isso, seriam considerados abandonados dois princípios fundamentais do Estado Constitucional Moderno: a equação Estado-Sociedade e a vinculação a um território concreto do Estado (OLIVIERO; CRUZ, 2014, p.159-160). No sentido, portanto, de construção deste modelo de Estado transnacional e trabalhando a chamada “integração" transnacional, está se falando de algo muito além da mera cooperação.

A sociedade global e os mercados interdependentes desafiam o Estado e as Organizações Internacionais (como a ONU, OMC, União Europeia) uma vez serem instados a resolver conflitos transnacionais como xenofobia, refugiados, terrorismo, devastação ambiental, e também conflitos do consumidor agora globalizado. Não pensar globalmente acaba por mitigar a eficácia do combate a estes problemas, uma vez que operações e 
regulamentações conjuntas entre os agentes transnacionais podem contribuir para a distribuição de renda, segurança alimentar e promoção do desenvolvimento.

Inclusive, as fronteiras passam a ser definida de modo diferente, deixando de ser o começo para ser a chegada, "sempre precária e fluida por natureza, pois a fluidez torna-se condição indispensável da competição e do dinamismo da Sociedade global” (BECK, 1997, p.113).

O modelo de Estados transnacionais pode ser considerado 'híbrido', pois os Estados transnacionais são Estados não-nacionais, não territoriais, tornam-se assim uma instância do Espaço transnacional, com suas próprias competências e determinados pontos onde exercerá sua soberania. Além disso, o Estado nacional afirma um novo conceito de Estado, que reconhece a globalidade como um fato fundamental e incontestável em suas mais variadas dimensões e eleva a determinação e organização do âmbito transnacional à condição de chave para a nova determinação e a revitalização da política. (BECK, 1999, p. 193)

A Globalização, marco inicial para a construção do Estado transnacional, pode ser definida englobando três processos, que são o aumento extraordinária dos fluxos internacionais de bens, serviços e capitais, o acirramento da concorrência nos mercados internacionais e a maior integração entre os sistemas econômicos nacionais (GONÇALVES, 1998). O cenário internacional se volta, indubitavelmente, à ampliação de mercados consumidores, com a finalidade precípua das grandes corporações e de grupos econômicos de conquista um consumidor global, independente de sua nacionalidade ou domicílio. O foco é o seu potencial de consumo e seu poder aquisitivo.

Com o mercado de consumo ampliado a níveis internacionais, a Internet surge como instrumento de marketing e vendas para as empresas transnacionais; e como meio de compra para os consumidores globais. Em 2019, existem 4,19 bilhões de usuários de internet, um aumento de 366 milhões (9\%) em relação a janeiro de 2018. Existem mais de 11 novos usuários de internet por segundo, o que resulta em um milhão de novos usuários todos os dias (BIGCOMMERCE, 2019).

O uso do comércio eletrônico transformou as relações comerciais de modo a relativizar distâncias e limites territoriais que possam existir para que os cidadãos satisfaçam suas vontades enquanto consumidores. A Internet se consolida como meio de suprir crises no mercado interno e de divulgação de produtos e serviços em nível mundial, agregando valor às empresas e transformando o e-commerce no responsável pelo salto nos faturamentos. 
A Associação Brasileira de Comércio Eletrônico (ABComm) estima se deve atingir um volume de vendas de $\mathrm{R} \$ 79,9$ bilhões em 2019, além de um ticket médio de $\mathrm{R} \$ 301$ e 265 milhões de pedidos efetuados pelos consumidores online até o final do ano. ((ECOMMERCEBRASIL, 2019). No plano internacional, conforme dados divulgados em estudo realizado Serviço de Proteção ao Crédito (SPC Brasil) e pela Confederação Nacional de Dirigentes lojistas (CNDL), 22\% dos internautas têm o hábito de comprar em sites do exterior (E-COMMERCEBRASIL, 2017).

Este comércio online transnacional é chamado de E-commerce cross border, caracterizado pela internacionalização das operações do comércio eletrônico. Conforme estudo divulgado pela Pitney Bowes, 70\% dos compradores entrevistados de 12 países realizaram compras em sites internacionais no ano de 2017, um aumento de $6 \%$ em relação a 2016 (E-COMMERCEBRASIL, 2018). Uma segunda pesquisa confirma a evolução. De acordo com números de relatório do DHL, esse mercado será ampliado em 25\% até 2020. Com isso, ele alcançará vendas no valor de US\$ 900 bilhões no período (ECOMMERCEBRASIL, 2018). Segundo dados da Accenture, até 2020, mais de dois bilhões de consumidores online gastarão 3,4 trilhões de dólares no e-commerce. Apesar de as compras domésticas ainda representarem a maior parte das transações de e-commerce B2C, o cross border, com sua taxa de crescimento anual de quase $30 \%$, será decisivo para alavancar o mercado de comércio online (VTEX, 2018).

\section{Figura 01}

E-commerce cross border 2014-2020

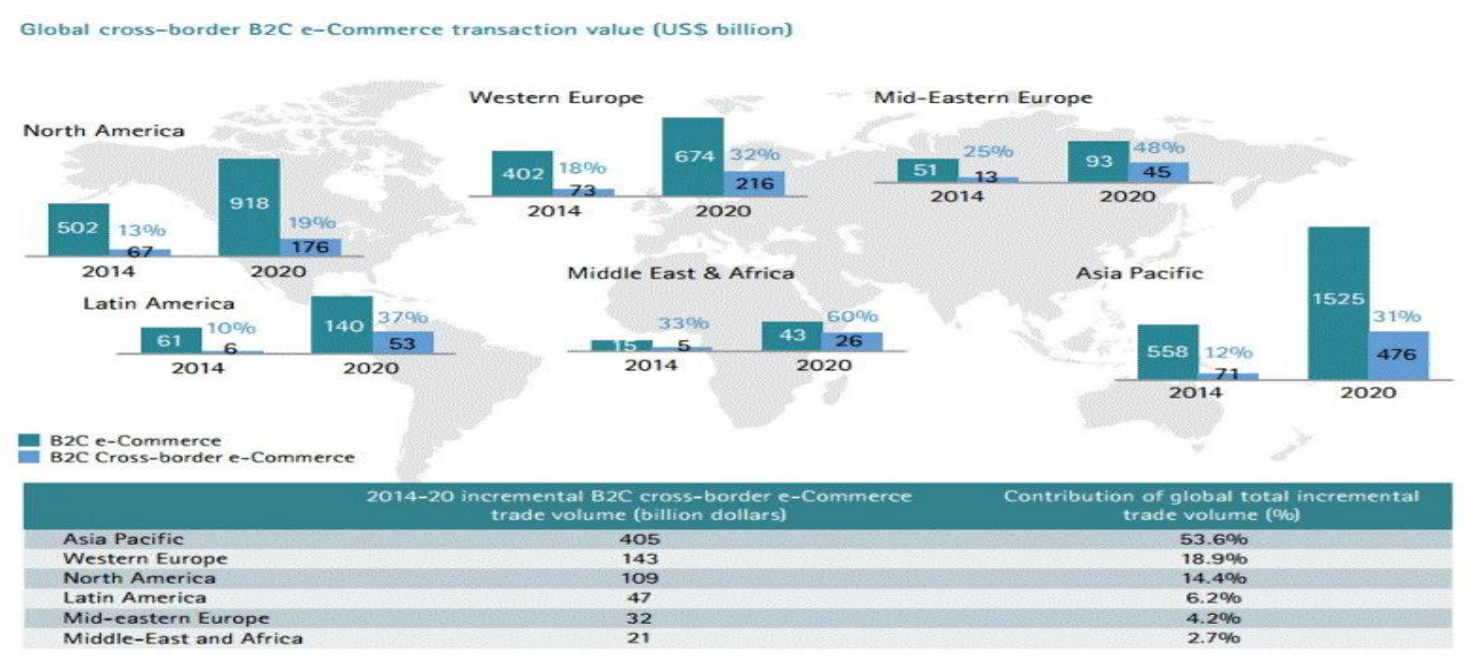

Fonte: Vtex, 2018. 
Dentro deste panorama, já há algum tempo a Organização Mundial do Comércio OMC - debate regras para trocas de dados entre empresas e prestadores de serviço de países diferentes, a tributação de serviços e bens transacionados entre distintas nações e formas de assegurar os direitos do consumidor em situações como na compra de bens e serviços em países distintos do seu. Porém, nada de concreto até hoje foi feito tendo em vista que cada país transaciona conforme seus próprios interesses.

\section{2 - O E-COMMERCE CROSS BORDER E OS CONTRATOS VIRTUAIS}

Comércio eletrônico, em simplória definição, são as transações comerciais realizadas à distância com uso de recursos eletrônicos. Contudo, existem inúmeras conceituações. Uma definição que vale a pena mencionar é a de que o comércio eletrônico pode ser definido com a compra e venda de produtos e bens pela Internet (NETO, 2001, p.29) e existem autores que deixam claro que o comércio eletrônico não é apenas aquele realizado através da Internet, mas abarca todos os tipos de contratação feita por meios tecnológicos.

Ressalta-se ainda que a definição de comércio eletrônico pode ser vista sob dois aspectos, segundo Cláudia Lima Marques: em sentido estrito, "como sendo uma das modalidades de contratação não presencial ou à distância para aquisição de produtos e serviços através de meio eletrônico ou via eletrônica"; e em sentido amplo, "como um novo método de fazer negócios através de sistemas e redes eletrônicas”. (MARQUES, 2004, p. 38). No caso em estudo, a análise recairá sobre o sentido estrito da definição, analisando a relação de consumo entre consumidor e fornecedor.

A diferença essencial entre o contrato de consumo tradicional e o eletrônico é a forma de disponibilização dos produtos e serviços, já que no caso do contrato eletrônico a disponibilização é feita através de sites ou correio eletrônico. Assim, o que caracteriza em sua essência o contrato eletrônico é o meio eletrônico utilizado, podendo esse uso ser de forma total ou parcial. De forma total, o fornecedor e o consumidor celebram toda a fase de negociação, compra e efetiva entrega do produto ou serviço pela via eletrônica; de forma parcial, efetuam a fase de negociação via e-mail e finalizam de forma presencial, inclusive com o envio do contrato impresso para assinatura de ambos os contratantes.

A grande maioria dos contratos de consumo firmados pela Internet possui a característica de serem adesivos, ou seja, o consumidor não tem opção de discutir as cláusulas contratuais; elas já estão pré-estabelecidas pelo fornecedor, restando ao consumidor apenas a 
opção de aceitar as condições ou não. No caso dos contratos eletrônicos internacionais, isso é agravado, pois ainda existe o fator "distância", o que dificulta ainda mais esse tipo de negociação.

Para que os contratos eletrônicos se efetivem, têm-se duas fases importantes na negociação: a proposta e a aceitação. A proposta é o momento inicial do contrato, ato pelo qual uma das partes solicita a manifestação de vontade da outra. No caso da contratação eletrônica, pode ser de forma imediata (via chat) ou via e-mail, com lapso de tempo para resposta. Essa proposta deve obedecer aos preceitos do Código Civil no caso das contratações feitas com consumidores no Brasil, que rege, em seu artigo 428, que a proposta só deixa de ser obrigatória nos casos em que a) feita de forma presencial e não for obtida resposta; b) haja retratação do proponente ante ou simultaneamente ao conhecimento da outra parte; c) ou ainda, em caso de feita a proposta entre ausentes, passa-se tempo suficiente e não há resposta da outra parte ${ }^{2}$.

$\mathrm{O}$ artigo $6^{\circ}$ do Decreto $\mathrm{n}^{\circ} .7 .962$ de 2013, que regulamenta o Código brasileiro consumerista - Lei $\mathrm{n}^{\circ}$ 8.078, de 11 de setembro de 1990 - para dispor sobre a contratação no comércio eletrônico, preceitua que "as contratações no comércio eletrônico deverão observar o cumprimento das condições da oferta, com a entrega dos produtos e serviços contratados, observados prazos, quantidade, qualidade e adequação".

Em se tratando dos contratos eletrônicos internacionais, a Lei modelo da Comissão das Nações Unidas para o Direito Comercial Internacional (UNCITRAL) aprovada através da Resolução $n^{\circ}$. 51/162 da ONU, determina em seu artigo 15, que o local de conclusão do contrato é aquele em que o destinatário tem a sede principal, independentemente do local de instalação do sistema informático, entendendo que a Internet é um meio de contratação e não um local físico. Essa definição vai ao encontro do que defendemos na relação consumerista internacional, devendo ser aplicada a legislação de domicílio do consumidor.

No caso dos contratos eletrônicos de consumo firmados pelos consumidores brasileiros, em âmbito nacional, o local da contratação deve ser entendido como sendo o do

\footnotetext{
${ }^{2}$ Artigo 428 do Código Civil: Deixa de ser obrigatória a proposta: I - se, feita a prazo à pessoa presente, não foi imediatamente aceita. Considera-se também presente a pessoa que contrata por telefone ou por meio de comunicação semelhante; II - se, feita sem prazo a pessoa ausente, tiver decorrido tempo suficiente para chegar a resposta ao conhecimento do proponente; III - se, feita a pessoa ausente, não tiver sido expedida a resposta dentro do prazo dado. IV - se, antes dela, ou simultaneamente, chegar ao conhecimento da outra parte a retratação do proponente.
} 
consumidor, nos termos do artigo 101 do Código de Defesa do consumidor ${ }^{3}$, para fins de propositura de ação de responsabilidade. Ao analisar o local de formação dos contratos eletrônicos internacionais de consumo deve-se ter em mente que são contratos firmados entre ausentes, onde o consumidor é parte mais frágil da relação e que o contrato é efetivamente celebrado onde está sendo proposto. Neste sentido, qualquer ação relativa a direitos do consumidor nesse tipo de contato deve ser proposta no domicílio do consumidor, até pelo fato de que muitas vezes o consumidor nem sabe onde reside o seu fornecedor.

Uma diferenciação importante a ser feita é entre os contratos internacionais de comércio e os de consumo. Aqueles são caracterizados pela relação entre empresários, profissionais, que negociam com fins comerciais, que tendem a ser duradouras, abrir mercados e estabelecer relações negociais cooperativas e duradouras. Os contratos de consumo internacionais, ao contrário, geralmente são descontínuos, não apresentando longa duração. A relação, neste caso, tem de um lado temos um comerciante, e de outro, um consumidor como destinatário final de produto ou serviço.

Há um claro desequilíbrio na relação contratual, uma vez que o consumidor é atraído a adquirir produtos por métodos massivos e agressivos de estratégias de marketing, o que o leva a firmar contratos de consumo sem saber exatamente seu conteúdo (MARQUES, 2011, p.45).

\section{3 - A REGULAMENTAÇÃO DO E-COMMERCE BRASILEIRO}

O comércio eletrônico, como já demonstrado, é um negócio firmado entre duas partes, comprador e fornecedor por meio de um contrato que é regido no Brasil pelo Código Civil de 2002. Por óbvio, para ser considerado válido, deve seguir os mesmos requisitos do negócio jurídico, previstos no artigo 104 daquele diploma, como agente capaz, objeto lícito, possível, determinado ou determinável e forma prescrita ou não defesa em lei. Atendidos estes requisitos para a efetivação do contrato, se houver uma relação de consumo entre um fornecedor e um consumidor, o CDC também incidirá, assim como o Decreto $\mathrm{n}^{\circ}$ 7.962, que veio para regulamentar dentro do CDC as relações firmadas no e-commerce nacional.

${ }^{3}$ Art. 101. Na ação de responsabilidade civil do fornecedor de produtos e serviços, sem prejuízo do disposto nos Capítulos I e II deste título, serão observadas as seguintes normas: I - a ação pode ser proposta no domicílio do autor. 
Alguns pontos importantes deste Decreto precisam ser destacados. Um, é a obrigação de apresentação de um sumário do contrato antes do fechamento do pedido do consumidor, com as informações necessárias ao pleno exercício do direito de escolha do consumidor, como o tipo de contratação, condições de pagamento, prazo de entrega, vencimento de obrigações, condições para rescisão contratual, além das cláusulas que limitem direitos. Este sumário é uma espécie de pré-contrato de compra e venda ou de prestação de serviços.

Outro ponto interessante do Decreto é a obrigação para que os sites de comércio eletrônico disponibilizem, em local de destaque e de fácil visualização, a razão social ou nome completo do fornecedor, bem como o número do CPF ou CNPJ, dependendo se pessoa física ou jurídica, obrigando inclusive que os fornecedores informem nos sites seus endereços tanto físico e eletrônico.

Com a globalização e a Era da tecnologia, as transações realizadas eletronicamente cresceram exponencialmente as conexões ultrapassam as fronteiras nacionais, formando um mercado transnacional. Identificar quais as normas que incidirão para solucionar os problemas decorrentes do e-commerce transnacional é um desafio, que se intensifica pela necessidade de entendimento a nível estatal, de forma a padronizar as normas internacionalmente a medida do possível. Dentro desta realidade, percebe-se que é de se constatar a existência de uma tendência de os Estados soberanos adotarem regras uniformes, em matéria de comércio eletrônico, para gerar alguma espécie de certeza aos comerciantes internacionais (FINKELSTEIN, 2011, p.126).

Para tanto, surge um novo cenário global para o Estado, que compartilha esferas de seu poder, aceitando ser regulamentado por normas consensuais aceitas pelos participantes da sociedade internacional. A antiga ideia de concentração de poder apenas nas mãos do Estado está superada e surge um novo modelo de Estado, obrigando o mesmo a administrar parcerias com outras fontes de poder, como as empresas, organizações sociais e empresas transnacionais.

A legislação brasileira tenta organizar a parte processual do e-commerce internacional quando envolve consumidor brasileiro, com alguns dispositivos importantes. A Lei de Introdução às normas do direito brasileiro em seu art. $9^{\circ}$, define que "Para qualificar e reger as obrigações, aplicar-se á a lei do país em que se constituírem. §2. A obrigação resultante do contrato reputa-se constituída no lugar em que residir o proponente." Na relação de consumo no comércio eletrônico, o proponente é aquele que propõe à realização do 
negócio. Por conseguinte, o Código Civil Brasileiro em seu art. 435 dispõe que "Reputar-se á celebrado o contrato no lugar em que foi proposto".

O novel código de processo civil (NCPC) dispõe em seu art. 21 que é competente a autoridade judiciária brasileira quando o réu estiver domiciliado no Brasil, independente da sua nacionalidade e que se a pessoa jurídica tiver filial, no Brasil, entende-se que ela tem domicílio no Brasil. Continua ainda o artigo 22 do NCPC dizendo que "Compete, ainda, à autoridade judiciária brasileira processar e julgar as ações: II - decorrentes de relações de consumo, quando o consumidor tiver domicílio ou residência no Brasil. Assim, fica clarividente que no Brasil, quanto a jurisdição correspondente para resolver eventuais litígios no comércio eletrônico, haverá aplicação do Código Civil brasileiro, e nos casos de relações de consumo, aplica-se ainda o CDC, sem prejuízo de outras leis e princípios cabíveis.

$\mathrm{O}$ acórdão inaugural e referência no Brasil foi o clássico Recurso Especial $\mathrm{n}^{\circ}$. 63.981/SP proferido no ano de 2000, envolvendo a Panasonic do Brasil LTDA e um consumidor brasileiro (STJ, 2000). No caso em tela, o consumidor adquiriu um produto com defeito nos Estados Unidos da Panasonic americana. Percebe-se que o contrato de consumo foi firmado com a empresa norte americana, mas a Justiça brasileira entendeu que a Panasonic do Brasil deveria arcar com o dano e indenizar o consumidor. Neste caso reconheceu-se a transnacionalidade das empresas que tem atuação mundial, independente da sua localização. Isso facilita imensamente os consumidores, pois no caso de compras internacionais (virtuais ou não) de empresas que atuem a nível mundial, o consumidor poderá acioná-las em seu domicílio através de suas filiais, algo que foi ratificado no Decreto de 2013.

Mas será que existem problemas no e-commerce cross border? Segundo pesquisa divulgada pela Sociedade Brasileira de Varejo e Consumo (SBVC, 2019), alguns problemas como atraso na entrega e produtos danificados ocorrem, gerando percentual e $15 \%$ de produtos que precisam de troca, mas ela não ocorre.

\section{Figura 02}

Satisfação dos consumidores no E-commerce cross border 


\section{Maioria dos consumidores está satisfeita com as compras online em sites de outros países}

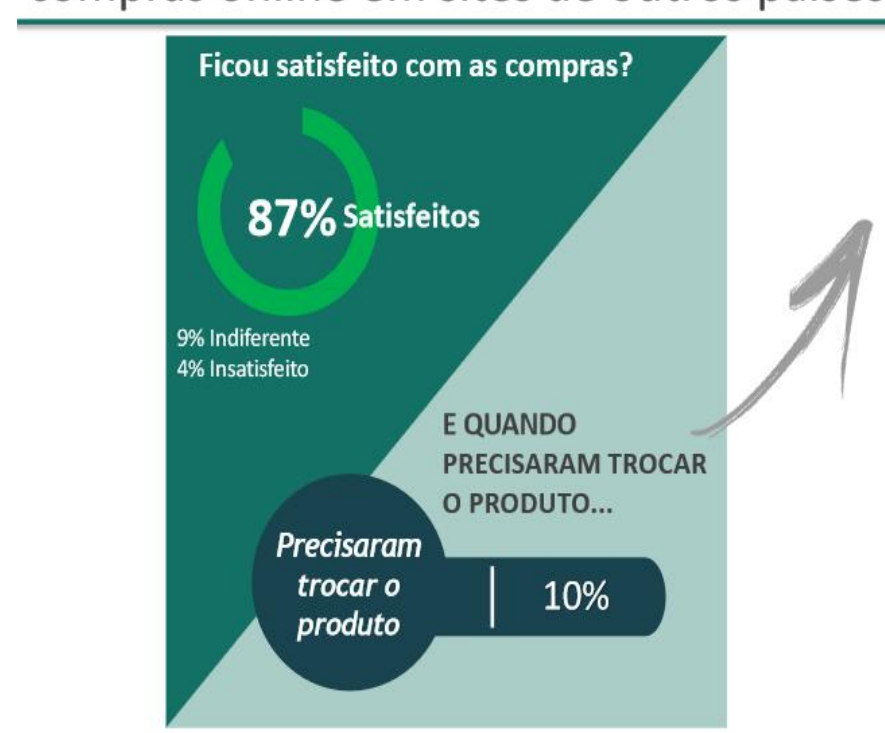

...PRINCIPAL MÉTODO

UTILIZADO FOI:

$34 \%$ via Correios;

$15 \%$ através de reembolso/ crédito;

$15 \%$ a troca não foi feita;

$7 \%$ troca por outro produto;

$29 \%$ Năo sei/ Não lembro e Outros

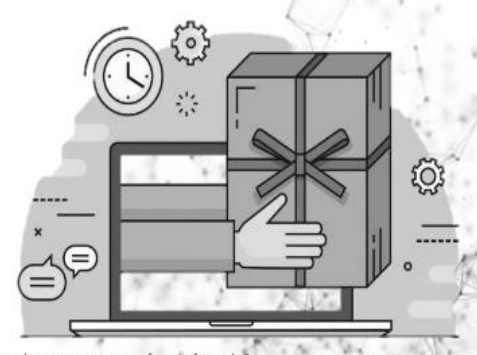

SBVC

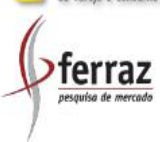

P23. Você ficou satisfeito com as suas compras em site/ aplicativo de outros paises?

P24. Foi necessária a troca de algum produto comprado em sites internacionais? P24a. Qual foi o método utilizado pelo site/ aplicativo de outro país para que a troca fossé efetuada? Base:427 entrevistas; Base P24a: 41 entrevistas

Fonte: SBVC, 2019.

A tendência é os números se elevarem, tanto de transações quanto de problemas, uma vez que esse modelo está se incorporando ao comportamento de consumo do brasileiro. Isso porque conforme a mesma pesquisa, $68 \%$ dos brasileiros pretendem comprar mais em sites de outros países (SBVC, 2019), o que desafia fortemente a ordem jurídica e a proteção do consumidor.

\section{4 - AS DIFICULDADES PARA O CONSUMIDOR BRASILEIRO NO E-COMMERCE CROSS BORDER}

O Direito internacional Privado - Dipr - surge neste contexto para auxiliar nos conflitos que possam envolver mais de um ordenamento jurídico, como é o caso do ecommerce cross border. Consiste em um complexo de normas e princípios de regulação que, atuando nos diversos ordenamentos legais ou convencionais, estabelece qual o direito aplicável para resolver conflitos de Leis ou sistemas, envolvendo relações jurídicas de natureza privada ou pública, com referências internacionais ou interlocais (STRENGER, 2000, p.27).

Ainda, conforme a escola Anglo-Saxônica, o Direito Internacional Privado deve auxiliar na resposta a três questões (ARAÚJO, 2003, p.30): qual a justiça competente para 
solucionar a lide, dizendo onde a ação deve ser proposta; qual lei aplicável ao caso, como aplicá-la e como se regem as provas; e ainda, como serão efetivados os atos processuais e de que forma sentença produzirá efeitos no país-sede do fornecedor.

Os Estados, neste contexto, criam normas de DIPr para amenizar os conflitos chamados de "conflitos de $1^{\circ}$ grau", que são aqueles que derivam da avocação de cada Estado de sua jurisdição para solucionar conflitos que tenham a presença do elemento estrangeiro. Então, a cooperação internacional vem para tentar harmonizar as regras de DIPr, através dos Tratados e Convenções Internacionais, pois com a diversidade de normas internas, surgem os conflitos chamados de "conflitos de $2^{\circ}$ grau", que dizem respeito à divergência entre estes direitos (LIMA, 2016, p.90). Neste sentido, o desenvolvimento do DIPr atual possui o desafio de alcançar a proteção dos agentes mais fracos (no caso, o consumidor) dentro do contexto da sociedade internacional totalmente globalizada e interdependente. O Direito internacional historicamente desenvolveu-se para solucionar litígios entre partes que estavam no mesmo patamar, em condições de igualdade. O novo objetivo que surge é equilibrar as relações entre a parte mais fraca da relação e a outra mais forte, entregando uma prestação jurisdicional mais justa possível.

A Resolução 39/248 da ONU foi aprovada em 1985 e teve como objetivo principal formular uma carta específica contendo traços gerais destinados a proteção do consumidor, voltada a todos os Países. Nesta carta, a ONU reconhece a fragilidade do consumidor, que enfrenta desequilíbrio em termos econômicos, níveis educacionais e no poder de negociação. Este documento traz ainda os princípios gerais para o alcance dos objetivos nele traçados, destacando a necessidade de políticas fortes de proteção, principalmente no tocante à saúde, segurança, interesses econômicos, informação adequada, educação, bem como a manutenção pelos governos de órgãos para fiscalização das empresas.

Assim, esta Resolução reconheceu e positivou a vulnerabilidade do consumidor no plano internacional e influenciou consideravelmente a criação de normas nacionais para a proteção do consumidor em vários países do mundo. Atualmente, este Princípio da proteção do consumidor é internacionalmente reconhecido como Direito Humano Fundamental. Em nosso ordenamento jurídico, foi positivado pelo art. $5^{\circ}$, XXXII da Constituição Federal ${ }^{4}$ e pela

\footnotetext{
${ }^{4}$ Art. $5^{\circ}$ Todos são iguais perante a lei, sem distinção de qualquer natureza, garantindo-se aos brasileiros e aos estrangeiros residentes no País a inviolabilidade do direito à vida, à liberdade, à
} 
Lei 8.078/90.

A Resolução traz normas que não possuem caráter imperativo, cabendo a cada Estado implementá-las da forma que considerar mais eficaz, conforme sua realidade e necessidade. Inclusive, o item II do Anexo da Resolução traz como Princípio Geral a ideia de que os governos devem formular e fortalecer uma política enérgica de proteção ao consumidor, estabelecendo as prioridades conforme as circunstâncias econômicas e sociais e necessidades de cada população. Posteriormente, esta Resolução foi ampliada pelo Conselho Social na Resolução 1999/7 de 26 de julho de 1999, que a revisou e a ratificou na Assembleia Geral na Resolução 70/186 de 22 de dezembro de 2015.

Dentre os tipos normativos que podem contribuir sobremaneira para uma harmonização no plano da legislação internacional para regular mercados transfronteiriços são os Princípios, mais adaptáveis a esta realidade tão velozmente modificada pela dinâmica das relações sociais e empresariais. Na visão do importante autor contemporâneo Ronald Dworkin, os Princípios adquirem força normativa, constituindo-se em uma das espécies do gênero "norma" (ao lado das regras). O autor denomina de "princípio" um padrão que deve ser observado, não porque vá promover o assegurar uma situação econômica, política ou social, considerada desejada, mas porque é uma exigência de justiça ou equidade, ou alguma outra dimensão da moralidade (DWORKIN, 2002, p.36).

Este reconhecimento da normatividade e da vinculação dos Princípios se torna pressuposto de continuidade do sistema jurídico, até porque eles refletem os valores da própria sociedade. Assim, prevalecendo os Princípios em busca de uma harmonização jurídica internacional, é imprescindível citar o Instituto Internacional para a Unificação do Direito Privado (UNIDROIT), que sendo uma organização intergovernamental independente, tem por objetivo estudar meios de harmonizar e de coordenar o direito privado entre os Estados e de preparar gradualmente a adoção por estes de uma legislação de direito privado uniforme.

Os Princípios do UNIDROIT constituem-se em um instrumento de harmonização do Direito do Comércio Internacional, como alternativa ao uso do direito positivo elaborado pelos Estados Nacionais, mediante tratados e convenções internacionais. É voltada aos contratos internacionais de comércio, porém possui alguns Princípios - não todos - que poderiam ser estendidos às relações internacionais de consumo, como se perceberá a seguir.

igualdade, à segurança e à propriedade, nos termos seguintes:[...] XXXII - o Estado promoverá, na forma da lei, a defesa do consumidor. 
O Princípio da Primazia das Regras Imperativas trazido pela UNIDROIT no artigo $1.4^{5}$, indica uma limitação da autonomia da vontade das partes, restringindo-a, pois essas normas imperativas são de ordem pública (integrante do direito nacional, internacional ou supranacional), estando presentes hoje tanto nos contratos internos como nos de âmbito internacional. Como se viu, as normas voltadas a proteção do consumidor são de ordem pública, fazendo com que este Princípio também seja aplicável às relações internacionais de consumo. velozmente alterada (UNIDROIT, 2016, p.11).

Um fator interessante que pode ser encampado como argumento para a responsabilização a nível global das empresas no mercado de consumo transnacional é o fato de que a tutela conferida às marcas por meio das patentes pode fortalecer o argumento à proteção do consumidor que adquire um produto diretamente no exterior ou compra à distância mercadoria de marca explorada no mercado brasileiro. Se o direito de propriedade industrial fornece vantagem ao dono da marca, permitindo sua exploração exclusiva no mercado nacional, o contraponto é que o direito do consumidor pode reconhecer uma responsabilidade do Direito consumerista oriunda desse reconhecimento global (VASCONCELOS, 2014, p.07).

Importante ressaltar aqui que não se trata da discussão entre teorias monista e dualista do Direito Internacional, na tentativa de saber qual deverá prevalecer em caso de conflitos entre o CDC brasileiro e Tratados internacionais. Isso porque, recentemente, o Supremo Tribunal Federal, em sede de Repercussão geral, (Recurso Extraordinário 636.331$\mathrm{RJ}$, de relatoria do ministro Gilmar Mendes) tratou do conflito aparente entre CDC e as convenções sobre transporte aéreo internacional no tocante à indenização por extravio de bagagem. Neste caso, o STF fixou a tese de que as normas e os tratados internacionais limitadores da responsabilidade das transportadoras aéreas de passageiros, especialmente as Convenções de Varsóvia e Montreal, têm prevalência em relação ao Código de Defesa do Consumidor, não violando o art. 178 da Constituição brasileira (STF, 2018). Neste caso, há normativa, há um Tratado que regulamenta o caso concreto, não cabendo alegação de anomia.

Avanço importante foi dado em outubro de 2016, em que a UNCTAD (Conferência das Nações Unidas em Comércio e Desenvolvimento) promoveu a Primeira Reunião do

\footnotetext{
${ }^{5}$ Article 1.4 (Mandatory rules): Nothing in these Principles shall restrict the application of mandatory rules, whether of national, international or supranational origin, which are applicable in accordance with the relevant rules of private international law.
} 
Grupo de Experts em Direito do Consumidor (IGE), em Genebra, com o objetivo primordial de estabelecer um programa de trabalho em política do consumidor em nível global para o período 2016-2020 (UNCTAD, 2016). Nesta reunião, foram editadas diretrizes para a proteção dos consumidores em nível global, como os itens 63, 64 e 65 deste documento que tratam sobre comércio eletrônico.

No item 63, a diretriz orienta que os Estados-Membros "devem esforçar-se por melhorar a confiança no comércio eletrônico pelo desenvolvimento contínuo do políticas transparentes e eficazes de defesa do consumidor, assegurando proteção que não é menor do que a oferecida em outras formas de comércio" (UNCTAD, 2016). Já o item 64, preceitua que os Estados devem "rever as políticas de proteção ao consumidor para acomodar as características especiais do comércio eletrônico, deixando consumidores e empresas informados e conscientes dos seus direitos e obrigações no mercado digital". (UNCTAD, 2016). Ainda, o item 65 indica que os Estados podem considerar as normas internacionais sobre comércio eletrônico para "adaptar essas orientações e normas às suas circunstâncias econômicas, sociais e ambientais, bem como colaborar com outros Estados Membros em sua implementação através das fronteiras". (UNCTAD, 2016).

É importante frisar que a interferência estatal para garantir a proteção dos Direitos do consumidor não contraria os princípios clássicos do livre comércio e da livre concorrência. Pelo contrário, esta proteção aos consumidores colabora para a regulamentação e equilíbrio de mercado, garantindo que o exercício desta liberdade não afete direitos individuais e coletivos. Na proposta feita por Cláudia Lima Marques ao Comitê Jurídico Interamericano - CIJ/OEA da Organização dos Estados Americanos para a uma Convenção Interamericana de Direito Internacional Privado, ela indica que há uma tendência atual de desenvolvimento de normas imperativas em matéria de consumo em conjunto com a regulamentação nos processos de integração regional (MARQUES, 2011, p.65).

De todo modo, regular o E-commerce cross border será o desafio dos próximos anos diante do aumento significativo das trocas comerciais como demonstrado nesta pesquisa. $\mathrm{O}$ fato de a ONU estar avançando neste tema é de se destacar, inclusive com o acontecimento da quarta edição da Reunião do Grupo Intergovernamental de Especialistas em Legislação e Política de Proteção do Consumidor, realizado pela UNCTAD em julho de 2019 em Genebra, na Suíça (MJSP, 2019). A compatibilização entre possíveis conflitos das normas, nacional e internacional, a depender de como o Brasil vai referendar a legislação internacional 
internamente, sem dúvida, é um desafio legislativo, especialmente pelo nível avançado do nosso código consumerista e a incipiente regulamentação internacional sobre o tema.

\section{CONSIDERAÇÕES FINAIS}

A revolução tecnológica e dos meios de comunicação construiu uma sociedade transnacional, de modelo consumista, com padrões de conduta globalizados, que cria necessidades humanas nem sempre compatíveis com a renda ou o perfil dos consumidores. A Internet trouxe para ordem internacional o desafio de se adaptar à nova realidade socioeconômica. A interação, seja ela pessoal ou profissional, ocorre de forma contínua e duradoura, mesmo que as pessoas jamais se encontrem: é a revolução nas relações humanas, objeto do desenvolvimento do Direito e do ordenamento jurídico internacional.

É claro que, dentre as várias formas de integração, as trocas comerciais são as que mais colaboram no processo de interdependência econômica mundial, e o comércio eletrônico transnacional é a mais nova realidade presente na vida dos Estados, das empresas e dos internautas. Abordar como este comércio funciona e está regulamentado, relacionando-o com a situação de vulnerabilidade do consumidor foi o desafio, e a partir disso, algumas conclusões podem ser relatadas. O nascimento deste $e$-commerce cross border é o retrato da superação das fronteiras. Não existe um ordenamento jurídico voltado ao comércio eletrônico internacional no âmbito interno dos países, nem mesmo no contexto internacional que possa reger as relações internacionais de compras pela Internet. $\mathrm{O}$ fornecedor dispõe de inúmeras ferramentas de publicidade e vendas pela Internet e se oferece ao consumidor a comodidade e possibilidade de consumir produtos mundiais. Porém, em caso de lides decorrentes deste contrato de consumo internacional pela via eletrônica, sempre fica uma dúvida acerca da competência territorial para julgamento, direito material aplicável e formas de se dar efetividade às sentenças favoráveis aos consumidores.

No Brasil, foi editado o Decreto $n^{\circ}$. 7.962/2013 que regulamentou a Lei $n^{\circ} 8.078$, de 11 de setembro de 1990, para dispor sobre a contratação no comércio eletrônico no âmbito interno, mas que ainda é incipiente para dirimir conflitos entre o cenário nacional e transnacional. No cenário internacional, a ONU, por meio da Lei modelo sobre comércio eletrônico da UNCITRAL, trouxe alguns conceitos para incorporação aos ordenamentos jurídicos nacionais, em virtude da maioria não abranger este tipo de contratação. A União 
Europeia, via OCDE, preconizou algumas regras sobre proteção ao consumidor, proibição de propaganda enganosa e reconhecimento da fragilidade do consumidor.

O MERCOSUL, por meio do Protocolo de Santa Maria, também busca firmar princípios para tutelar os consumidores deste bloco econômico. Tem-se ainda a UNIDROIT, a Convenção de Roma e as normas em geral de DIPr que, de uma forma ou de outra, trazem um Princípio, um conceito ou uma regra consumerista que podem ser adotadas para a regulamentação deste comércio e que possa ser aceita por todos os países de forma global.

O ordenamento jurídico brasileiro vem tentando através de seus juristas proporcionar uma guarida ao seu consumidor, dando interpretação conforme o Código de Defesa do Consumidor Brasileiro, no sentido de atribuir competência ao domicílio do mesmo para dirimir quaisquer problemas consumeristas. Quando se faz uma análise sistêmica deste dispositivo, que tem como pano de fundo a vulnerabilidade do consumidor, com a Resolução 39/248 da Organização das Nações Unidas (posteriormente ampliada pelo Conselho Social na resolução 1999/7 de 26 de julho de 1999, e revisou e adotou pela Assembleia Geral na resolução 70/186 de 22 de dezembro de 2015), pode-se estender esta interpretação à relação consumerista internacional eletrônica, defendendo que o consumidor possa demandar em seu domicílio, pois este dificilmente se deslocaria ao estrangeiro para litigar.

Assim, percebe-se a importância de se buscar uma harmonização material de proteção do consumidor na ordem internacional, por meio da instituição de Normas únicas a reger as relações transnacionais de consumo (eletrônicas ou não). Essa padronização depende, necessariamente, da concessão dos Estados de parcela de seu poder para que a cooperação internacional alcance o objetivo de proteger, não apenas o cidadão nacional, mas sim, enxergando-o como um cidadão do mundo virtual, que não está limitado a fronteiras territoriais, culturais ou sociais. Tanto que os Princípios do UNIDROIT trazem esta mesma visão, instruindo no sentido da harmonização do Direito do Comércio Internacional, como alternativa ao uso do direito positivo elaborado pelos Estados Nacionais, mediante tratados e convenções internacionais.

O Direito Internacional Privado assume papel relevante neste contexto. Ao se propor esta regulamentação do comércio eletrônico em âmbito global, a fim de se proteger o consumidor virtual, sabe-se das nuances que isso implica, principalmente porque passa pela submissão estatal a mais um tipo de regulação e até, um possível controle supranacional. 
Porém, o sucesso deste desafio está em focar não apenas no Estado, mas principalmente na sociedade eletrônica, que pode ser a maior aliada no controle e fiscalização deste comércio.

Talvez, o foco deva ser, principalmente, a divulgação de informações e orientação ao consumidor sobre como deve proceder quando contrata eletronicamente no mercado internacional e quais cautelas deve tomar para evitar problemas futuros. Então, caso ainda assim haja o surgimento da eventual lide consumerista, que ela seja solucionada nos padrões firmados pelos Estados em âmbito internacional, seja via justiça estatal, seja inclusive através da arbitragem.

\section{REFERÊNCIAS DAS FONTES CITADAS}

ARAÚJO, Nádia. Direito Internacional Privado: teoria e prática brasileira. Rio de Janeiro: Renovar, 2003.

BECK, Ulrich. Que és la globalización. Buenos Aires: Paidós, 1997.

O que é globalização? Equívocos do globalismo. Respostas à globalização. Tradução de André Carone. São Paulo: Paz e Terra, 1999. Disponível em <https://www.academia.edu/12652876/globaliza\%C3\%A7\%C3\%A3o_Ulrich_Beck_tradu\%C 3\%A7\%C3\%A3o_de_Andr\%C3\%A9_Carone.S\%C3\%A3o_Paulo_Paz_e_Terra_1999. Acesso em 18.08.2019.

BIGCOMMERCE. The Global Omni-Channel Consumer Shopping Research Report. Pesquisa disponibilizada em 2019. Disponível em <https://www.bigcommerce.com/blog/cross-border-ecommerce-guide/\#undefined>. Acesso em 16.08.2019.

BRASIL. Constituição da República Federativa do Brasil de 1988. Disponível em <http://www.planalto.gov.br/ccivil_03/constituicao/constituicao.htm> Acesso em 10.08.2019.

Lei $n^{\circ} .10 .406$ de 10 de Janeiro de 2002. Código Civil brasileiro. Disponível em <http://www.planalto.gov.br/ccivil_03/leis/2002/110406.htm>. Acesso em 10.08.2019.

Lei $\mathrm{n}^{\circ}$. 8.078 de 11 de Setembro de 1990. Código de defesa do Consumidor. Disponível em <http://www.planalto.gov.br/ccivil_03/leis/18078.htm> Acesso em 10.08.2019.

CAPRA, Fritjof. Conexões Ocultas. Ciência para uma vida sustentável (Trad. Marcelo Brandão Cipolla). São Paulo: Editora Cultrix, 2002.

DWORKIN, Ronald. Levando os direitos a sério. Trad Nelson Boeira. São Paulo: Martins Fontes,2002. 
E-COMMERCE BRASIL. Um em cada cinco internautas compra em e-commerce internacional. Pesquisa disponível em <https://www.ecommercebrasil.com.br/noticias/umem-cada-cinco-internautas-compra-em-e-commerce-internacional/> . Acesso em 23.08.2019.

<https://www.ecommercebrasil.com.br/artigos/o-panorama-do-ecommerce-cross-border/>. Pesquisa divulgada em 2018. Acesso em 10.08.2019.

FINKELSTEIN, Maria Eugênia. Direito do Comércio Eletrônico. 2a Edição. Ed. Campus Jurídico, 2011.

GONÇALVES, Reinaldo. Globalização Econômica e Vulnerabilidade Externa. Trabalho apresentado no Seminário "Economia Global, Integração Regional e Desenvolvimento Sustentável", Colégio do Brasil e Universidade Federal Fluminense, Rio de Janeiro, 17 de abril de 1998.

LIMA, Eduardo Weiss Martins. Proteção do consumidor brasileiro no comércio eletrônico internacional. São Paulo: Atlas, 2016.

MARQUES, Cláudia Lima. Confiança no comércio eletrônico e a proteção ao direito do consumidor: (um estudo dos negócios jurídicos de consumo no comércio eletrônico). São Paulo: Revista dos Tribunais, 2004.

A insuficiente proteção do consumidor nas normas de Direito Internacional Privado - Da necessidade de uma Convenção Interamericana (CIDIP) sobre a lei aplicável a alguns contratos e relações de consumo. CJI/OEA, Washington/Rio de Janeiro, 2001.

Contratos no Código de Defesa do Consumidor. $5^{\text {a }}$ ed. São Paulo: Editora Revista dos Tribunais, 2005.

MINISTÉRIO DA JUSTIÇA E SEGURANÇA PÚBLICA. Debate sobre políticas globais para aprimoramento dos direitos do consumidor. Notícia veiculada em 11 de Julho de 2019. Disponível em < https://www.justica.gov.br/news/collective-nitf-content1562880133.74> Acesso em 23.08.2019.

OLIVIERO, Maurizio; CRUZ, Paulo Márcio. Reflexões sobre o Direito Transnacional. UNIVALI, 2014. Disponível em: <http://www.univali.br/periodicos>

SOCIEDADE BRASILEIRA DE VAREJO E CONSUMO. Pesquisa sobre perfil dos consumidores do e-commerce cross border. Disponível em < http://sbvc.com.br/oconsumidorbrasileiro/> Acesso em 21.08.2019.

STF. Recurso Extraordinário $\quad \mathbf{n}^{\mathbf{0}}$.636.331. Disponível em <http://stf.jus.br/portal/jurisprudenciaRepercussao/verAndamentoProcesso. asp?incidente=404 
0813\&numeroProcesso=636331\&classeProcesso=RE\&numeroTema=210. $>$ Acesso em 10.07.2019.

STJ. Recurso Especial $\mathbf{n}^{\mathbf{0}}$. 63.981. Disponível em < https://stj.jusbrasil.com.br/jurisprudencia/330218/recurso-especial-resp-63981-sp-19950018349-8>.

STRENGER, Irineu. Direito Internacional Privado. 4 ed. atual e amp. São Paulo: LTr, 2000 .

UNCTAD. United Nations Conference on Trade and Development. United Nations Guidelines on Consumer Protection. Disponível em $<$ https://unctad.org/en/Pages/DITC/CompetitionLaw/UN-Guidelines-on-ConsumerProtection.aspx>.Acesso em 13.08.2019.

UNIDROIT. UNIDROIT Principles of International Commercial Contracts. Rome: 2016.

VASCONCELOS, Raphael Carvalho de. Consumo Transnacional: O Consumidor, sua proteção e o mercado. Disponível em: <http://www.direitorp.usp.br/wpcontent/uploads/2014/11/RaphaelVasconcelosConsumotransnacional.pdf $>$. Acesso em 23.08.2019.

VETEX. Os desafios da venda cross border em países emergentes. Disponível em $<$ https://www.vtex.com/pt-br/blog/operacoes/os-desafios-da-venda-cross-border-em-paisesemergentes/>. Acesso em 09.08.2019.

VOLPI NETO, Angelo. Comércio Eletrônico: direito e segurança. Curitiba: Juruá, 2001. 